\title{
Concentración de la tierra y las Zonas de Interés de Desarrollo Rural, Económico y Social (Zidres) en los Montes de María. María La Baja y Carmen de Bolívar*
}

\author{
Daniel Alzate Moraa
}

\begin{abstract}
Resumen: La concentración de la tierra en América Latina y en Colombia tiende a profundizarse. A pesar de los esfuerzos del Estado por revertir esta tendencia, el fenómeno de la concentración de la tierra se intensifica, en especial, en aquellas regiones que han sido fuertemente afectadas por el conflicto armado interno, como es el caso de Los Montes de María. A partir de información cuantitativa y cualitativa se expone el contexto social y político de los municipios de María La Baja y el Carmen de Bolívar para analizar la estructura agraria, y se demuestra su tendencia general hacia una mayor concentración de la tierra. A partir de esta información se presenta la relación que tiene dicha estructura agraria con el modelo de desarrollo de las Zonas de Interés de Desarrollo Rural, Económico y Social (Zidres) aprobado por la ley 1676 de 2016.
\end{abstract}

Palabras clave: Zidres; acaparamiento de tierra; Montes de María; desarrollo rural; derecho agrario

Recibido: 06 de octubre de 2019 Aceptado: 25 de marzo de 2020

Disponible en línea: 28 de septiembre de 2020

Cómo citar: Alzate Mora, D. (2020). Concentración de la tierra y las Zonas de Interés de Desarrollo Rural, Económico y Social (Zidres) en los Montes de María. María La Baja y Carmen de Bolívar. Prolegómenos, 23(46), 51-70. doi: https://doi.org/10.18359/prole.4309

* Artículo de investigación resultado del proyecto "Los conflictos por la tierra en Colombia. Un análisis socio-jurídico en perspectiva comparada (municipios de María La Baja y Carmen de Bolívar, Montes de María)" que se financió con recursos provenientes del Fondo Nacional de Financiamiento para la Ciencia, la Tecnología, y la Innovación "Francisco José de Caldas" de Colciencias.

a Doctor en Derecho de la Universidad del Rosario, Colombia. Máster Europeo en Historia y Comparación de las Instituciones Políticas y Jurídicas de los países de la Europa Mediterránea, de las Universidades de Milán (Italia), Messina (Italia) y Córdoba (España). Especialista en derechos humanos y estudios críticos del derecho, Consejo Latinoamericano de Ciencias Sociales; Escuela Latinoamericana de Políticas Públicas. Especialista en derecho de tierras, Universidad Externado de Colombia. Abogado de la Universidad de los Andes. Jurisdicción Especial para la Paz, Bogotá, Colombia.

Correo electrónico: Daniel.Alzate@urosario.edu.co 


\title{
Land concentration and Rural, Economic, and Social Development Interest Zones (Zidres) in los Montes de María, María La Baja and Carmen de Bolívar
}

\begin{abstract}
Land concentration in Latin America and in Colombia tends to grow. Despite the state's effort to revert that trend, the land concentration phenomenon intensifies, specially, in those regions that have been strongly affected by the internal armed conflict, such as the "Los Montes de Maria". Based on quantitative and qualitative information, the social and political context of María La Baja and Carmen de Bolívar is presented to analyze the agrarian structure, and the trend to higher land concentration is proven. From this information the relation such agrarian structure has with the development model of the Rural, Economic and Social Development Interest Zones (Zidres for its Spanish Acronym) approved by Law 1676 of 2016.
\end{abstract}

Keywords: zidres; land grabbing; Montes de María; rural development; agrarian right

Concentração da terra e das Zonas de Interesse de Desenvolvimento Rural, Econômico e Social nos Montes de María. María La Baja e Carmen de Bolívar

\begin{abstract}
Resumo: A concentração da terra na América Latina e na Colômbia tende a se aprofundar. Apesar dos esforços dos Estado para inverter essa tendência, o fenômeno da concentração da terra é intensificado, em especial, nas regiões que vêm sendo fortemente afetadas pelo conflito armado interno, como é o caso de Los Montes de María. A partir de informação quantitativa e qualitativa, é exposto o contexto social e político dos municípios de María La Baja e de Carmen de Bolívar para analisar a estrutura agrária, e é demonstrada sua tendência geral a uma maior concentração da terra. Com base nesses dados, é apresentada a relação que essa estrutura agrária tem com o modelo de desenvolvimento das Zonas de Interesse de Desenvolvimento Rural, Econômico e Social (Zidres), aprovado pela Lei 1.676 de 2016.
\end{abstract}

Palavras-chave: zidres; monopolização de terra; Montes de María; desenvolvimento rural; direito agrário 


\section{Introducción}

Los procesos de acaparamiento y concentración de la tierra de alcance mundial tienen en América Latina profundas raíces históricas que nos remontan a las épocas coloniales, vínculos que permanecen vigentes y hacen de la región el espacio del mundo más desigual en términos de acceso a la tierra (Mollet, 2016).

De acuerdo con el instrumento por excelencia para medir la desigualdad, el coeficiente de Gini ${ }^{1}$, para la tierra en América Latina cifras de Oxfam (2016) indican que en la región alcanza un valor de 0,79 , que en comparación con otros espacios geográficos (Europa 0,57; África 0,56; Asia 0,55) representa la extrema desigualdad en falta de acceso a tierras en la región (Bennewitz, 2017).

Este índice de desigualdad en el acceso a la tierra en América Latina, de 0,79, se acompasa con los índices arrojados para Colombia, como uno de los países con mayor desigualdad con un coeficiente Gini de 0,897 , apenas superado por Uruguay $(0,93)$ y Chile $(0,91)$ (Fajardo, 2018, p. 17). Para 2014, Colombia fue uno de los más desiguales de la región en el acceso a la tierra a nivel mundial, evidenciando así la problemática y centralidad del estudio del uso y usufructo de la tierra en Colombia (Oxfam América, 2017).

El problema agrario en Colombia ha venido adquiriendo una mayor relevancia ante el curso de los acontecimientos de los últimos años. Con la ley 1448 de 2011 se adoptan medidas de justicia transicional y reparación a las víctimas, entre las que resalta la restitución de tierras. El acuerdo de paz con la guerrilla de las FARC-EP trajo consigo una reforma rural integral, que busca aportar una mejor distribución de la tierra y acceso a los servicios de los pobladores rurales que permitan su desarrollo

1 El coeficiente de Gini mide la desigualdad entre los factores de estudio; un valor de cero corresponde a la perfecta igualdad (los actores poseen el mismo activo) y un valor de uno representa la extrema desigualdad (un actor posee el total de los activos, mientras que el resto no posee ningún activo). y el "buen vivir" ${ }^{2}$ Pero, al mismo tiempo que se adelantan estos esfuerzos, se desarrollan políticas que privilegian el desarrollo de agronegocios y modelos de alianzas productivas con campesinos y grandes empresarios del sector agrario; estas políticas no guardan plena coherencia con las medidas de justicia transicional y el escenario de implementación de los acuerdos de paz en el posconflicto.

Un ejemplo de este último tipo de políticas con orientación hacia los agronegocios es la Ley 1776 de 2016 (Congreso de Colombia, 2016) por la cual se crean las Zonas de Interés de Desarrollo Rural, Económico y Social (Zidres), como un novedoso modelo de ordenamiento social y productivo de los territorios a nivel nacional. El planteamiento de este modelo es crear unos espacios territoriales, con características específicas que define la ley, para el desarrollo de proyectos agroindustriales que asocien a los campesinos y los trabajadores agrarios; espacios para supuestamente generar desarrollo económico y acceso a la tierra de los campesinos. Sin embargo, el planteamiento de las Zidres ha sido criticado por reducir las tierras disponibles para la reforma agraria; además, las Zidres introducen una serie de disposiciones normativas tendientes al saneamiento de los procesos de acaparamiento irregular de la tierra, que en la mayoría de los casos es producto de la violencia del conflicto armado en Colombia.

2 El concepto de "buen vivir" aparece incorporado en el acuerdo de paz entre la guerrilla de las FARCEP y el Estado colombiano. Específicamente, se hace mención del concepto en el punto 1, "Reforma Rural Integral”. Existe una amplia literatura sobre el desarrollo de las ideas asociadas al concepto de "buen vivir", en su formulación por los pueblos indígenas ecuatorianos, o "vivir bien”, como lo hacen los pueblos indígenas de Bolivia. Siguiendo a Gudynas (2016) el "buen vivir” hace referencia al conjunto de críticas radicales al desarrollo capitalista, pero también como un planteamiento de alternativas a la destrucción aparejada a la acumulación de capital. Y como parte de los procesos sociales que vivieron Ecuador y Bolivia en la década de los años 90, que van a lograr una consagración en sus textos constitucionales, como principio, valor y fines del Estado. Al respecto ver Gudynas (2011, 2016); Acosta (2013); Sempere (2010). 
La extrema desigualdad en Colombia tiene a su vez una compleja e imbricada relación con el conflicto armado, no solo como una de sus causas, como lo afirman los aportes desde perspectivas críticas al informe presentado por la Comisión Histórica del Conflicto Armado y sus Víctimas (2015), sino también como un aspecto que perpetúa el conflicto social. La falta de acceso a la tierra está asociada directamente a mayores niveles de pobreza y a la negación sistemática de derechos fundamentales como la dignidad humana, la salud, la educación, la protección social, la vivienda y el mínimo vital, entre otros.

Uno de los escenarios del conflicto por el acceso a la tierra lo ejemplifica la región de Montes de María en el Caribe colombiano. Ubicada en el centro de los departamentos de Bolívar y Sucre, es una región geográfica conformada por quince municipios. Los Montes de María ha sido un territorio en disputa donde hicieron y hacen presencia actores armados como las guerrillas de las FARC-EP, el ELN y el EPL, bloques paramilitares y fuerzas del Estado; es uno de los más golpeados por el desplazamiento forzado y la violencia sistemática.

En particular, los municipios de María La Baja y El Carmen de Bolívar ejemplifican las nuevas formas de violencia legal que se impone sobre sus pobladores. En estos municipios confluye un primer momento caracterizado por el desplazamiento forzado, despojo de tierras, masacres y asesinatos selectivos de líderes sociales; justamente después de estos actos de violencia, hay un segundo momento en el que se desarrollan proyectos agroindustriales de gran escala, en especial la siembra de palma africana y productos maderables, entre otros usos.

En razón a lo anterior, nos proponemos como objetivo general analizar, desde una perspectiva sociojurídica, los conflictos por la tierra en los municipios de María La Baja y El Carmen de Bolívar, ubicados en la región de los Montes de María, en relación con los planteamientos de la ley Zidres, haciendo énfasis en la concentración de la tierra. Para ello, se realizó una revisión documental con el fin de exponer el contexto sociopolítico de los dos municipios señalados; posteriormente, con información entregada por la Unidad de Planificación Rural Agropecuaria (UPRA), para compararlo con la estructura de tenencia de la tierra y, a partir de allí, exponer algunas conclusiones sobre los posibles efectos de la ley Zidres en los territorios objeto de estudio.

\section{Breve contextualización de María La Baja en la subregión de Montes de María}

El municipio de María La Baja, el cual hace parte de la subregión de los Montes de María en el Caribe colombiano, tiene aproximadamente $547 \mathrm{~km}^{2}$, correspondientes al 2,1\% de la superficie total del departamento de Bolívar. María La Baja limita por el norte con el municipio de Arjona, al este con los municipios de Mahates y San Juan Nepomuceno, al sur con los municipios de San Jacinto y El Carmen de Bolívar y al oeste con el municipio de San Onofre (Indepaz, 2013); ver Figura 1.

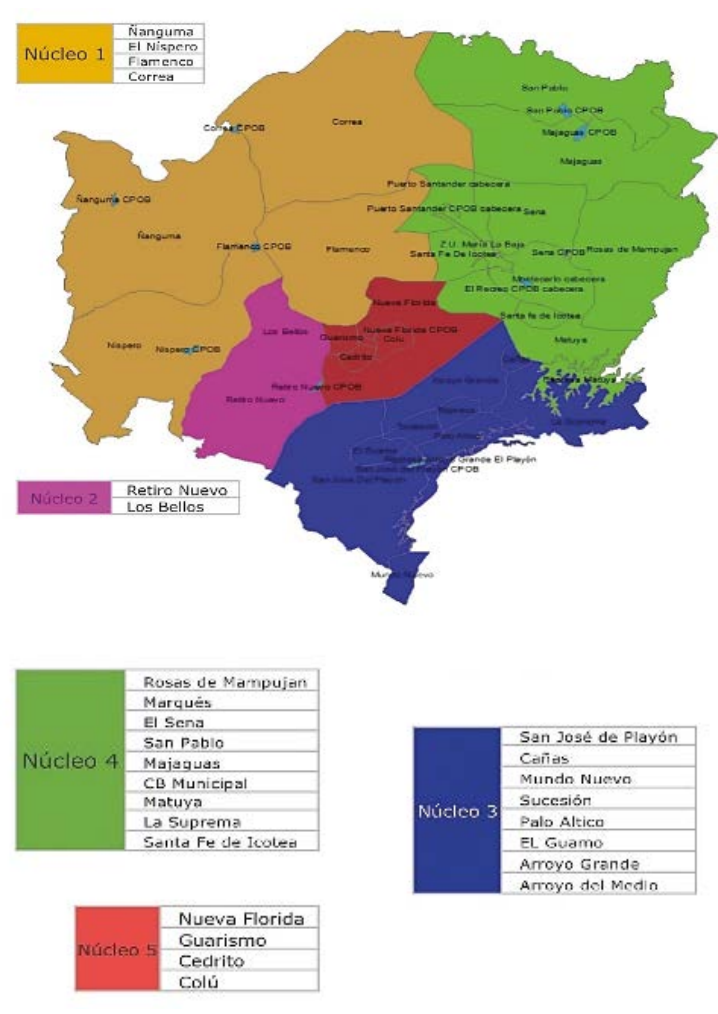

Figura 1. Mapa de María La Baja en la subregión de Montes de María.

Fuente: Juníeles (2017, s. p.). 
María La Baja cuenta con once corregimientos, once caseríos y diez veredas. Según información de la Alcaldía, una de sus principales características es que:

[...] esta zona produce condiciones favorables por la cercanía del agua para el desarrollo de la agricultura y la ganadería. Se encuentra en las faldas de los Montes de María, con un suelo que tiene un $90 \%$ apto para la agricultura y unos recursos hidráulicos con una ciénaga llamada la Ciénaga de María La Baja, es una de las más grandes de Colombia que se encuentra al norte de la cabecera municipal y es rica en recursos piscícolas (Alcaldía de María La Baja, 2016).

María La Baja es uno de los municipios con mayor vocación agropecuaria en la región de Montes de María, configurándose en un territorio altamente demandado por diferentes sectores sociales como son el del pequeño campesino, el gran latifundista, la empresa agroindustrial, entre otros actores en disputa por el potencial productivo de dichas tierras.

La conflictividad en María La Baja se evidencia en las transformaciones en la utilización de sus tierras fértiles: al principio con cultivos orientados hacia el sostenimiento de las economías campesinas, los cuales persisten pero en una menor proporción; posteriormente, para dar paso al modelo de la agroindustria a finales del siglo xx y comienzos del siglo XxI, en particular el cultivo de la palma africana, con graves problemas ambientales, sociales y económicos para María La Baja (Moreno, 2016, p. 51).

Así mismo, el territorio es utilizado para la cría de ganado, la industria avícola y la pesca, entre otros productos cárnicos o alimenticios; usos derivados de la alta calidad de los suelos y sus condiciones climáticas e hidrográficas, como lo ilustra la siguiente tabla (Tabla 1).

Tabla 1. Usos del suelo en María La Baja

\begin{tabular}{|c|c|c|c|c|c|}
\hline Tipo de uso & $\begin{array}{l}\text { Descripción del uso en el } \\
\text { municipio }\end{array}$ & $\begin{array}{l}\text { Extensión } \\
\text { del uso } \\
\text { actual(Has) }\end{array}$ & $\begin{array}{l}\% \text { de uso } \\
\text { actual }\end{array}$ & $\begin{array}{l}\text { Extensión del } \\
\text { uso potencial } \\
\text { (Has) }\end{array}$ & $\begin{array}{l}\% \text { de uso } \\
\text { potencial }\end{array}$ \\
\hline Agrícola & $\begin{array}{l}\text { Cultivos permanentes y transitorios. } \\
\text { Palma africana, yuca, maíz, plátano, } \\
\text { ñame, arroz. }\end{array}$ & $31.761,46$ & $58,53 \%$ & $25.067,8$ & $46,18 \%$ \\
\hline Agrícola Frutal & No aplica. & 0 & $0 \%$ & $6.703,66$ & $12,36 \%$ \\
\hline Agropecuario & $\begin{array}{l}\text { Actividades para un sistema de } \\
\text { producción campesina y de bajo nivel } \\
\text { tecnológico. }\end{array}$ & $2.842,59$ & $5,24 \%$ & $2.842,9$ & 5,24 \\
\hline Agrícola Forestal & $\begin{array}{l}\text { Se realiza cercade la cabecera } \\
\text { municipalAgricola forestal }\end{array}$ & $7.352,68 \%$ & $13,55 \%$ & $7.352,68 \%$ & $13,55 \%$ \\
\hline $\begin{array}{l}\text { Bosque productor } \\
\text { protector }\end{array}$ & $\begin{array}{l}\text { Se ubica en el corregimiento de San } \\
\text { Pablo, Isla de Punta Borda e Isla } \\
\text { Carabalí. }\end{array}$ & $2.587,66$ & $4,77 \%$ & $2.587,66$ & $4,77 \%$ \\
\hline Cuerpos de agua & $\begin{array}{l}\text { Se utilizan en el plano de inundación } \\
\text { del Canal de Dique. }\end{array}$ & $5.694,35$ & $10,49 \%$ & $5.694,35$ & $10,49 \%$ \\
\hline $\begin{array}{l}\text { Pecuario } \\
\text { (Paastoreo } \\
\text { Extensivo) }\end{array}$ & $\begin{array}{l}\text { Potereros en pastos naturales e } \\
\text { introducidosy rastrojos en menor } \\
\text { proporción. Las tierras de rastrojos } \\
\text { en Munguía, Mampuján, Playón. }\end{array}$ & $3.629,32$ & $6,69 \%$ & $3.629,32$ & $6,69 \%$ \\
\hline Residencial & Inmuebles habitacionales. & $397,82 \%$ & $0,73 \%$ & 397,82 & $0,73 \%$ \\
\hline Total & & $54.265,878$ & $100 \%$ & $54,265,88$ & $100 \%$ \\
\hline
\end{tabular}

Fuente: PNUD (2015a, p. 14). 


\section{Análisis sociohistórico de María La Baja}

Después de la reforma y contrarreforma agraria de las leyes 200 de 1936 y 100 de 1944 respectivamente, se impulsó la entrega de tierras a campesinos tras la expedición de la ley 135 de 1961 y sus modificaciones, como la Ley 1 de 1968. Bajo el liderazgo del Incora, institución llamada a desarrollar la reforma social agraria en el país, junto con la compra de tierras en María La Baja para dotar a las familias campesinas de tierras, se buscaba generar las condiciones mínimas para la subsistencia de su población (Incora, 2002).

Este proceso de entrega de tierras por parte del Incora fue acompañado por la puesta en marcha del distrito de riego en María La Baja en la década de los años sesenta del siglo $\mathrm{xx}$, como fuente de maximización y control productivo. Este proyecto está circunscrito por la Revolución Verde ${ }^{3}$ impulsada en el país por el programa "Alianza para el Progreso" de Estados Unidos y bajo el gobierno de Carlos Lleras Restrepo en Colombia (Pontificia Universidad Javeriana, 2016).

El proyecto del distrito de riego (cofinanciado por el Banco Interamericano de Desarrollo) se desarrolló con el fin de generar un espacio planificado y seguro para la producción agropecuaria en aproximadamente 25.000 hectáreas; también

3 "La agricultura era un componente clave para el 'desarrollo', la extensión del modelo económico industrial de los países del Norte a los 'países menos desarrollados' del Sur. A la modernización de la agricultura, basada en la industrialización de los insumos agrícolas, le llamaron la 'Revolución Verde'. A pesar de que muchos dicen que la Revolución Verde salvó al mundo del hambre, ésta permitió que las compañías del Norte monopolizaran las semillas y los insumos agrícolas. Además, significó la pérdida del $90 \%$ de la agrobiodiversidad de los países del Sur, el cambio a una economía agrícola mundial basada en el petróleo, el desplazamiento de millones de campesinos a laderas frágiles, la tala de los bosques y al crecimiento de barrios urbanos pobres. Contrariamente a lo que muchos creen, la Revolución Verde produjo la misma cantidad de hambrientos que los que salvó del hambre” (Holt-Giménez y Raj, 2012, p. 23). para dotar a los municipios de Arjona, Mahates y María La Baja de canales fluviales, con el fin de irrigar las tierras con conexiones a cuerpos naturales, como son las distintas ciénagas de la región. Este proceso contó con la construcción de embalses como el de Arroyo Hondo (Pontificia Universidad Javeriana, 2016).

Este proyecto de distrito de riego dotó a la región de condiciones ejemplares para la producción agraria y pecuaria en el país, lo que conllevó a que diferentes actores se disputaran estos territorios. En particular, en el municipio de María La Baja, el que sufrió el desplazamiento masivo de los campesinos favorecidos por el entonces Incora en la década de los años sesenta y principio de los años setenta; desplazamiento realizado por grupos de latifundistas y terratenientes, por medio de actos cada vez más violentos, bajo el auspicio del Estado colombiano, sea por acción u omisión, con el antecedente del denominado Pacto de Chicoral en 1972 (Ibáñez, 2008, p. 15).

Este proceso fue acompañado por la estigmatización del movimiento campesino de la Asociación Nacional de Usuarios Campesinos de Colombia (ANUC) línea Sincelejo, por parte de los grandes latifundistas y el mismo Estado colombiano; este último los consideraba como una estructura apoyada por, y subsidiaria de, los diferentes movimientos guerrilleros, que encontraron en el municipio y la región un sustrato importante debido a los conflictos sociales alrededor del país (Molano, 2011).

Ante este contexto de campesinos organizados, movimientos guerrilleros asentados en el territorio, latifundistas y terratenientes con grandes intereses y la incorporación de las estructuras paramilitares en la región, se configuró un masivo desplazamiento de familias campesinas de la región de los Montes de María y en particular de María La Baja. Fue causado por medio del asesinato selectivo, la criminalización y la estigmatización de líderes sociales, campesinos y políticos como fuente de control del territorio; así mismo se dio la incorporación de sus tierras a los grandes latifundios, por medio del genocidio como práctica social de control económico-político.

Otra condición que influyó en el desplazamiento de los campesinos fue la alta informalidad de la tenencia de la tierra, causada por la inexistente y 
pasiva institucionalidad estatal, lo que incitó a las tácticas de los ejércitos paramilitares al despojo (Juníeles, 2017, p. 17; Reyes, 2016, p. 233). El crimen del desplazamiento forzado en los Montes de María y en María La Baja alcanzó niveles especialmente altos: "[...] así, tenemos un total acumulado de 159.879 personas expulsadas de la región hasta el mes de julio de 2010. Los municipios más afectados son Carmen de Bolívar, San Onofre, Ovejas y María La Baja” (Cubillos, 2011, p. 62). La Tabla 2, sobre el desplazamiento en algunos municipios de la subregión de Montes de María, evidencia el grado de afectación por el conflicto armado. En particular, la táctica de guerra del desplazamiento por parte de las fuerzas paramilitares en donde tuvo una mayor afectación fue en María La Baja, con un desplazamiento de 8.689 hombres, 8.417 mujeres y en concreto 3.731 hogares desplazados, caracterizando la expulsión masiva y póstuma acumulación de estas tierras en pocas manos.

Tabla 2. Las cifras de desplazamiento en algunos municipios de Montes de María

\begin{tabular}{|c|c|c|c|c|}
\hline 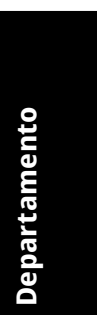 & 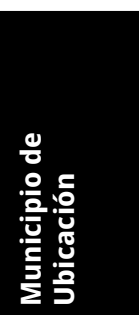 & 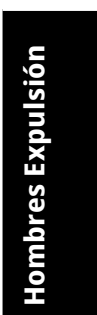 & 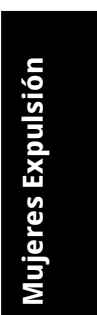 & 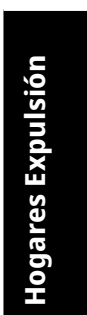 \\
\hline \multirow[t]{4}{*}{ Bolívar } & Córdoba & 6.133 & 5.499 & 2.388 \\
\hline & $\begin{array}{l}\text { El Carmen } \\
\text { de Bolívar }\end{array}$ & 38.338 & 30.520 & 14.175 \\
\hline & $\begin{array}{l}\text { María La } \\
\text { Baja }\end{array}$ & 8.689 & 8.417 & 3.731 \\
\hline & San Jacinto & 5.484 & 5.091 & 2.511 \\
\hline \multirow[t]{6}{*}{ Sucre } & Corozal & 449 & 452 & 218 \\
\hline & Morroa & 1.857 & 1.912 & 800 \\
\hline & Ovejas & 9.864 & 9.717 & 4.345 \\
\hline & Palmitos & 344 & 375 & 158 \\
\hline & $\begin{array}{l}\text { San } \\
\text { Onofre }\end{array}$ & 11.587 & 9.897 & 4.467 \\
\hline & Sincelejo & 2.793 & 2.479 & 1.183 \\
\hline \multicolumn{2}{|c|}{ Total general } & 85.538 & 74.359 & 33.976 \\
\hline
\end{tabular}

Fuente: elaboración propia a partir de Cubillos (2011, pp. 61-62).
Así mismo, bajo las políticas de apertura económica en el gobierno de César Gaviria, en su mandato entre los años 1990 y 1994, se evidencia el desplome sostenido de las condiciones internacionales de intercambio, lo que afectó directamente a los campesinos de las zonas de Montes de María y en particular los de María La Baja. Estos, tras la incorporación del distrito de riego, se concentraron en la producción de arroz impulsada por el Estado colombiano y vendría a propiciar en la década de los años noventa un menoscabo de las condiciones económicas de las familias campesinas.

Este contexto de crisis en las economías campesinas y la afectación directa por parte de los movimientos paramilitares, en particular el bloque norte de las Autodefensas Unidas de Colombia (AUC), fueron el fermento para la alta tasa de acumulación, desigualdad y pobreza en la región.

Entre 1998 y 2006 en María La Baja se desarrollaron aproximadamente 45 acciones violentas entre masacres, homicidios y secuestros selectivos. Con el punto más alto en 2001, cuando se realizaron por lo menos 20 actos violentos en contra de las comunidades de María La Baja, con el propósito directo de crear desplazamientos masivos acompañados por la acumulación de tierras. La Figura 2 ilustra las acciones violentas.

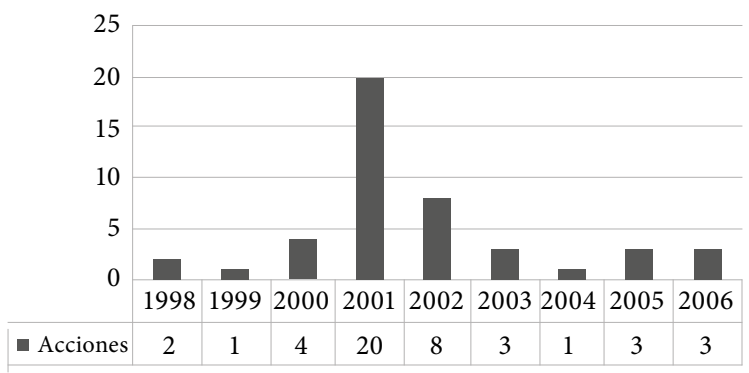

Figura 2. Número de acciones violentas entre 1998 y 2006 en María La Baja.

Fuente: Cubillos (2011, p. 70).

La economía del arroz en María La Baja estaba en crisis, luego de la transformación de la economía a principios de la década de los noventa del siglo xx, con la adopción de la apertura económica y sus consecuencias directas para los productores 
de arroz en el municipio. A partir de la libre competencia entre el pequeño campesino con baja composición orgánica del capital en Colombia y los procesos altamente industriales de los países metropolitanos, se estaba ante un escenario de competencia desigual. En este, el Gobierno implementaba políticas en contra de los intereses nacionales y de sus campesinos, para complacer los mandatos de organismos multilaterales como el Banco Mundial, el Fondo Monetario Internacional y el Banco Interamericano de Desarrollo, con sus recetas neoliberales para lograr el desarrollo económico en el supuesto mercado global.

Este proceso condujo a la adopción de la palma aceitera en la región, como fuente de recambio productivo, sustentado en las ventajas competitivas y comparativas en un mercado abierto y desregulado. Esta adopción se da después de la propuesta productiva impulsada por el Estado colombiano, en manos de Carlos Murgas Guerrero, exministro de agricultura en el primer año de la presidencia de Andrés Pastrana (1998-2002). Murgas fue quien diseñó, impulsó y se benefició de la reconversión productiva en la región de Montes de María y concretamente en María La Baja (Moreno, 2016, pp. 81, 82).

El gran poder político y económico del exministro Carlos Murgas produjo la imposición de la producción del aceite de palma bajo la plantación extensiva de la palma africana en María La Baja. Ello causó graves consecuencias ambientales, sociales, económicas y culturales debido a la irrupción de una nueva metodología de empleo y la subordinación del campesinado ante el control de la economía de conjunto y del territorio, para imponer el para qué, el qué y el cómo de la producción agraria (Bernstein, 2016).

Lo anterior, sin pasar por alto las graves tasas de violencia que se vivían para la época en la región, como fuente de acumulación de tierras que terminarían paradójicamente en manos de este sistema agroindustrial.

Otras graves violaciones de los derechos humanos afectaron particularmente a la población del municipio de María La Baja. Según datos oficiales, para el año 2010, después de la etapa de consolidación del paramilitarismo, habían sido desplazadas del municipio 17.680 personas, un número impresionante si se tiene en cuenta que la población del mismo es de 45.000 habitantes (Equipo Tierras y Víctimas, del Cinep/Programa por la Paz, 2012, p. 76).

Estas empresas agroindustriales, como es el caso de la palma africana en María La Baja, tienen como sustento la flexibilización e informalidad del trabajo propiciando la sobreexplotación de la fuerza laboral, debido a las necesidades de las comunidades, que se encuentran bajo el control territorial y la nula garantía estatal como fuente de soporte de estos proyectos.

Este nuevo modelo productivo concatenado con el desplazamiento masivo de las familias campesinas y las condiciones generadas por la apertura económica en Colombia, ocasionaron índices de concentración de tierras muy altas en el país: "el $1 \%$ de las fincas de mayor tamaño tienen en su poder el $81 \%$ de la tierra colombiana. El $19 \%$ de tierra restante se reparte entre el $99 \%$ de las fincas" (Paz y Latam, 2018, s. p.).

En María La Baja las condiciones de concentración de las tierras en pocas manos no son muy diferentes, como se puede evidenciar en la siguiente tabla (Tabla 3).

La Tabla 3 nos permite concluir que la concentración de la tierra en María La Baja es totalmente desigual. Mientras que solo un propietario pose 1.982,57 hectáreas, 623 propietarios poseen menos de 0,32 hectáreas; un total despropósito que atestigua el proceso de despojo y de acumulación a partir del desplazamiento forzado, la compra forzada para el control territorial y la manipulación por deudas insostenibles de las familias campesinas; entre otras dinámicas destructoras del campo y sus habitantes, los campesinos y campesinas.

Esta dinámica de concentración conlleva distintos conflictos en la región, como es el caso de los altos índices de pobreza e indigencia en María La Baja y claramente remarcado en la violación sistemática de los derechos laborales de los trabajadores agrarios; estos se encuentran anclados a la producción de aceite de palma y se ven oprimidos y explotados por un sistema de control tanto económico como político en la región, que perpetúa estas relaciones oprobiosas.

La concentración de la tierra en María La Baja ha derivado en tasas de pobreza que superan el $61 \%$ 
Tabla 3. Estructura y concentración de la Tierra en María La Baja en 2012

\begin{tabular}{|c|c|c|c|c|c|}
\hline Rango & & Área Ha. & $\begin{array}{l}\text { Propie- } \\
\text { tarios }\end{array}$ & N. ${ }^{\circ}$ predios & Ha. Prop. \\
\hline \multirow[t]{2}{*}{ Microfundio } & Inferior a 1 ha & 196,33 & 623 & 712 & 0,32 \\
\hline & 1 ha $<3$ ha & 816,48 & 509 & 574 & 1,60 \\
\hline \multirow[t]{2}{*}{ Minifundio } & 3 ha $<5$ ha & 839,37 & 259 & 276 & 3,24 \\
\hline & $5 \mathrm{ha}<10$ ha & $4.161,12$ & 668 & 532 & 6,23 \\
\hline \multirow[t]{2}{*}{ Pequeño } & 10 ha $<15$ ha & $3.857,85$ & 424 & 294 & 9,10 \\
\hline & $15 \mathrm{ha}<20 \mathrm{ha}$ & $2.440,21$ & 320 & 151 & 7,63 \\
\hline \multirow[t]{3}{*}{ Mediana } & 20 ha $<50$ ha & $9.021,15$ & 468 & 319 & 19,28 \\
\hline & 50 ha $<100$ ha & $4.840,01$ & 146 & 86 & 33,15 \\
\hline & 100 ha $<200 \mathrm{ha}$ & $4.539,57$ & 82 & 33 & 55,36 \\
\hline \multirow[t]{3}{*}{ Grande } & $200 \mathrm{ha}<500 \mathrm{ha}$ & $5.749,67$ & 67 & 15 & 85,82 \\
\hline & $500 \mathrm{ha}<1000 \mathrm{ha}$ & $1.029,52$ & 4 & 1 & 257,38 \\
\hline & 1000 ha $<2000$ ha & $1.982,57$ & 1 & 1 & $1.982,57$ \\
\hline
\end{tabular}

Fuente: elaboración propia a partir de PNUD (2015a, p. 20).

en el espacio urbano y de $58 \%$ en el espacio rural, con un total del 60 \% de la población de María La Baja en situación de pobreza. Es decir, que de cada diez personas, seis se encuentran en situación de pobreza en este municipio. Otro indicador diciente de la economía excluyente y opresora de María La Baja es el indicador de miseria de la población; se encuentra en lo urbano en $33,5 \%$ y en lo rural e $28,4 \%$, con un total de $30,4 \%$, uno de los índices más altos de todo el país. De lo anterior se desprende que de cada diez personas tres en María La Baja se encuentran en condición de miseria, como se puede evidenciar en la Tabla 4.
Es concluyente cómo María La Baja se ha visto afectada por los proyectos productivos de finales del siglo xx y se observan con gran preocupación las reformas productivas que vendrían a desembocar en las Zidres. Estas profundizarían la estructura desigual en el acceso a la tierra, así como que dichas políticas perpetuarían las condiciones de exclusión y sobreexplotación laboral en la región.

Las condiciones históricas de María La Baja, como su situación particular referente a los factores productivos, ambientales y espaciales, han ocasionado un sin número de intereses que han desembocado en una disputa abierta por el control

Tabla 4. Índices de Necesidades Básicas insatisfechas en María La Baja para el año 2011

\begin{tabular}{|c|c|c|c|}
\hline & Urbano & Rural & Total \\
\hline Personas Pobres por NBI & $61,6 \%$ & $58,9 \%$ & $60,0 \%$ \\
\hline $\begin{array}{l}\text { Personas en situación de } \\
\text { miseria }\end{array}$ & $33,5 \%$ & $28,4 \%$ & $30,4 \%$ \\
\hline Componente vivienda & Total & $5,9 \%$ & \\
\hline Componente servicios & Total & $20,9 \%$ & \\
\hline Componente inasistencia & Total & $6,8 \%$ & \\
\hline $\begin{array}{l}\text { Componente dependencia } \\
\text { económica }\end{array}$ & Total & $31 \%$ & \\
\hline
\end{tabular}

Fuente: elaboración propia a partir de PNUD (2015a, p. 41). 
de la tierra y el territorio; el Estado colombiano optó por apoyar a los terratenientes y los agronegocios, a costa de la dignidad humana de los campesinos y en general los habitantes de la ruralidad.

\section{Distribución de la tierra en María La Baja, Montes de María}

La concentración de la tierra en María La Baja tiende a profundizarse, perpetuando la desigualdad en el acceso y la posesión. Para rastrear la concentración de la tierra en María La Baja hemos tomado la información que nos fue entregada por la UPRA; realizamos una comparación de los años 2015 y 2019, para evidenciar que en un periodo corto de tiempo la tendencia es hacia la concentración de la tierra; para ello recurrimos a tres indicadores: i) el acrecentamiento del total de hectáreas de los predios, ii) el número de propietarios y iii) el número de predios.

Para el primer indicador, el del acrecimiento del total de hectáreas de los predios, se toma como referencia el área total de los predios en el año 2015, la cual ascendía a 39.473,85 hectáreas. Para el 2019 el área total correspondía a 54.766,82 hectáreas. De lo anterior podemos concluir que cuando se comparan los años 2015 y 2019 se obtiene que existió un crecimiento de 15.292,97 hectáreas totales de los predios en María la Baja. Esto es, que existió un incremento de aproximadamente el 38,5 $\%$ en tan solo cinco años del área en propiedad en María la Baja. Ver Figura 3.

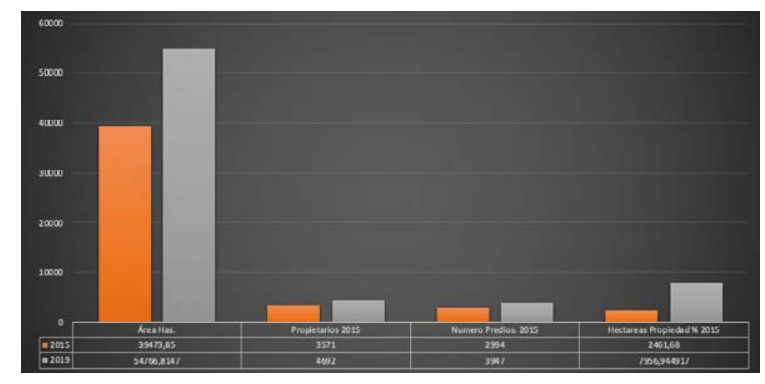

Figura 3. Totales de los datos de distribución de la tierra en María La Baja para los años 2015 y 2019.

Fuente: UPRA (2019).
Figura 4. Datos de la distribución de la tierra en María La Baja para el rango menor de una hectárea para los años 2015 y 2019.

Fuente: UPRA (2019, p. 14).

En el mismo periodo 2015-2019, en María La Baja se evidencia un aumento en el número de propietarios. En 2015 los propietarios eran 3.571. Para el año 2019 se incrementó en 4.692 propietarios. La diferencia entre los dos años es de un incremento de 941 propietarios nuevos. Esto representa un aumento del 26,4 \% aproximadamente. Sin embargo, el aumento en el número de propietarios no se traduce en una mejor redistribución en el acceso a la tierra; por el contrario, evidencia su mayor concentración. En efecto, si se compara que el crecimiento de las propiedades estuvo en el orden del 38,5\%, esta misma proporción no se compadece con el de los propietarios, que tan solo alcanzó el 26,4 \%. De lo que se desprende que la propiedad con el paso del tiempo tiende a concentrarse en pocas manos.

Así mismo, el número de predios en el periodo de estudio 2015-2019 pasó de 2.944 a 3.947 respectivamente, lo que significa un incremento de 1.003 predios, un acrecimiento del $34 \%$ en comparación con un 38,5\% de áreas en propiedad y $26,4 \%$ de propietarios. Esto recalca el sostenimiento de la concentración de la tierra en María La Baja en el periodo de estudio.

El análisis del número de predios debe ser complementado con su extensión, para no arrojar una imagen distorsionada de la realidad, según la cual un mayor número de predios representa una mejora en la distribución de la tierra. En efecto, cuando tomamos las propiedades inferiores a una hectárea, se incrementó su área total en 2015, de 196,3 hectáreas a 364,1 hectáreas en 2019. Por lo tanto, su crecimiento arroja como resultado un $85,4 \%$; 
mientras que el número de predios pasó de 712 a 1.130 , un crecimiento de $58,7 \%$; y, por último, los propietarios pasaron de 623 a 1.187, con un incremento de 90,5 \%.

En este rango de propiedades menores a una hectárea se evidencia un aumento en el número de propietarios y en el área de propiedad, poniendo de manifiesto un acrecentamiento en el campo urbano derivado del contexto de negociaciones de paz en el país, como se puede evidenciar en la Figura 4.

En los rangos más altos de extensión de la propiedad en María La Baja encontramos un crecimiento sostenido, con una intensificación en la concentración en pocas manos para el rango de 200 a 500 hectáreas. En 2015 el grupo de propietarios de tierra con una extensión entre las 200 y 500 hectáreas fue de 67, mientras que para el año 2019 el grupo de propietarios se redujo a 29. Se pasó de un porcentaje de áreas en promedio de 85,8 a 182 hectáreas por propietario, derivado de la reducción de propietarios, y un incremento en porcentaje de $115 \%$ entre 2015 y 2019, atestiguando la intensa concentración de las grandes propiedades en el municipio, como se puede evidenciar en la Figura 5.

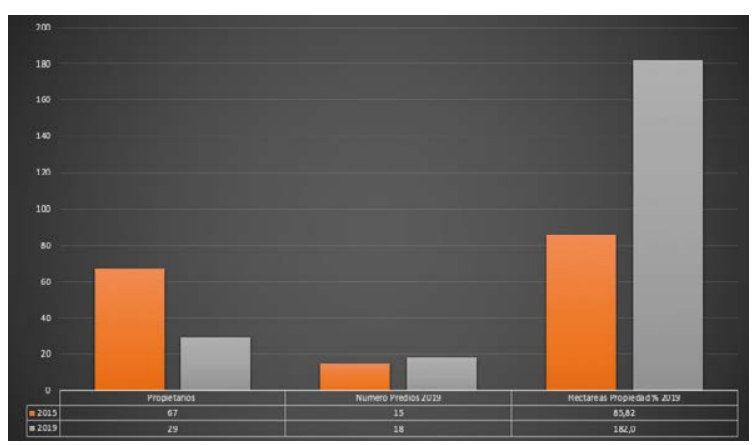

Figura 5. Total de los datos de la distribución de la tierra en María La Baja para el rango 200 a 500 hectáreas para los años 2015 y 2019.

Fuente: UPRA (2019, p. 18).

También se constata el incremento del área en el rango de 500 a 1000 hectáreas, pasando de 1.029,52 hectáreas a 2.310,65, un aumento de 1.281 hectáreas en total. El incremento representa más del $124 \%$. Aproximadamente ocho veces más que el área total de crecimiento del rango menor a una hectárea para el municipio de María la Baja.
Mientras tanto, los rangos de veinte a cincuenta hectáreas para el año 2019, en los que se encuentra la Unidad Agrícola Familiar, (UAF), se mantienen parcialmente inamovibles, pasando de 9.021 a 10.717 hectáreas con un crecimiento del $18 \%$; lo cual contrasta ampliamente con el crecimiento del $124 \%$ en el rango de 500 a 1.000 hectáreas, atestiguando la desigualdad en el acceso a la tierra en María La Baja y la poca o nula redistribución y adjudicación de tierras por parte del Estado.

Otra gran diferencia entre los datos de distribución entre 2015 y 2019 es que el mayor propietario en 2015 poseía un terreno con un área total de 1.982,57 hectáreas. Mientras que para el año 2019 el mayor poseedor tiene una superficie de 3.707 hectáreas, como se puede evidenciar en la Figura 6.

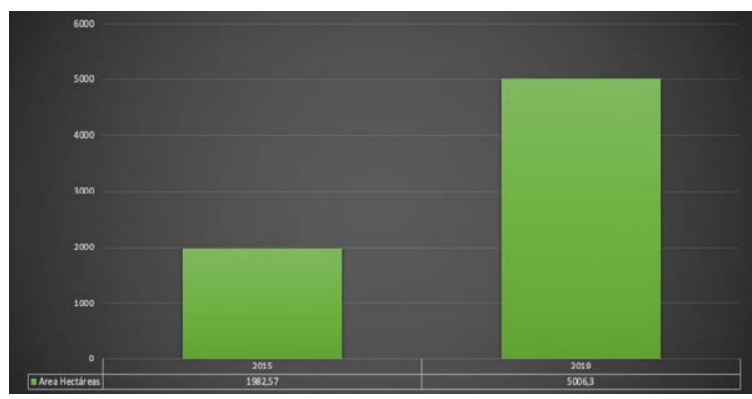

Figura 6. Hectáreas del mayor poseedor en María La Baja para los años 2015 y 2019.

Fuente: UPRA (2019, p. 21).

\section{Breve contextualización de EI Carmen de Bolívar en la subregión de Montes de María}

El municipio de El Carmen de Bolívar en la subregión de Montes de María (Figura 7) cuenta con

[...] una población de 73.457 habitantes para el año 2013 y tiene una superficie territorial de 93.400 hectáreas [...] el municipio de El Carmen de Bolívar limita por el norte con el municipio de San Jacinto, por el sur con el municipio de Ovejas (Sucre), por el este con los municipios de Zambrano y Córdoba, por el oeste con los municipios de Colosó y San Onofre (Sucre) (PNUD, 2015b, p. 11). 


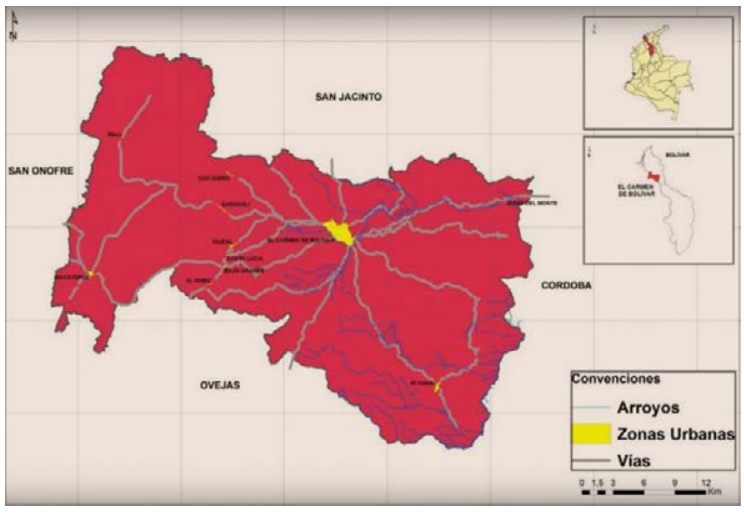

Figura 7. Mapa de la geolocalización del Municipio del Carmen de Bolívar.

Fuente: PNUD (2015b, p. 12).

El clima en El Carmen de Bolívar es tropical con gran influencia de los vientos alisios en varios meses del año, propiciando variaciones en la temperatura, humedad y precipitaciones. Estas características generan un ambiente ejemplar para el cultivo de alimentos como plátano, maíz, ñame y yuca entre otros productos de consumo y comercialización autóctona en la región (Agudelo y Cardozo, 1985).

El Carmen de Bolívar ha sido una región históricamente en disputa entre grandes intereses contrapuestos: el pequeño productor basado en la subsistencia agrofamiliar y la economía campesina, que se contraponen a los intereses de los grandes terratenientes y latifundistas por el control y dominio del territorio. El Carmen de Bolívar posee una alta tasa de violencia física, que se ha sostenido en el tiempo derivado de las cualidades agrícolas y la posición geoestratégica del municipio como corredor mercantil tanto de mercancías lícitas como ilícitas (González, 2017).

\section{Análisis sociohistórico de El Carmen de Bolívar}

La historia de El Carmen de Bolívar está marcada por la violencia, la que está determinada por relaciones socioeconómicas condicionadas por la exclusión al acceso del mayor sistema productivo en el país, la tierra. Este conflicto se ha mantenido constante desde los inicios de la República hasta nuestros días, y ha configurado un sinfín de conflictos que se centran en la tenencia, uso, usufructo y autonomía del territorio (Fajardo, 2017).

En las décadas de los años setenta a noventa del siglo $\mathrm{xx}$ las confrontaciones se hicieron cada vez más complejas con la interacción activa de grupos armados desde las guerrillas FARC-EP, ELN, entre otros, frente a la puesta en marcha de ejércitos irregulares, las Autodefensas Unidas de Colombia, apalancados por los grandes tenedores de tierra, bajo la protección del Ejército y el Estado colombiano. Tanto la aparición de estos actores como su concentración se realizó en todo el país, pero se vivió con un mayor índice de confrontación en la subregión de Montes de María y con holgura y desazón en El Carmen de Bolívar (Vega, 2015; Rivillas y Yepes, 2011).

La violencia en El Carmen de Bolívar ha generado graves impactos, como episodios de masacres, que desencadenaron acciones de desplazamiento forzado (Rivillas y Yepes, 2011, p. 53). Una de las causas del despojo y desplazamiento forzado sistemático en El Carmen de Bolívar está relacionada con su posición geoestratégica y la gran capacidad agrícola de la región, que lo hace un territorio apetecible por diferentes intereses. En la Tabla 5 pretendemos ilustrar este punto reseñando diversos usos del suelo: agrícola, forestal, agropecuario, bosques productores y protectores, y residencial, relacionando su extensión en hectáreas y su uso potencial.

El potencial agrario y pecuario de El Carmen de Bolívar es muy alto. El uso del territorio, en los últimos años, se ha encaminado a los cultivos permanentes como palma, aguacate, cacao, maderáceos y plátano. Su explotación es del 58,45 \% del territorio y al mismo tiempo se han generado afectaciones graves a los derechos humanos como resultado de las altas tasas de desplazamiento forzado y violencia en la región, desde la década de los noventa y su profundización en la primera década del siglo XxI.

Este uso del territorio conlleva a la identificación de conflictos históricos y también a los generados por la actual forma de explotación permanente y de carácter agroindustrial. Una causa del actual uso del territorio en El Carmen de Bolívar parte de la alta concentración de la tierra en el municipio, como se puede evidenciar en la Tabla 6 . 
Tabla 5. Uso actual y potencial del municipio de El Carmen de Bolívar

\begin{tabular}{|c|c|c|c|c|c|}
\hline Uso del suelo & $\begin{array}{l}\text { Descripción del uso en el } \\
\text { municipio }\end{array}$ & $\begin{array}{l}\text { Extensión uso } \\
\text { actual (hectáreas) }\end{array}$ & $\%$ & $\begin{array}{l}\text { Extensión } \\
\text { uso potencial } \\
\text { (hectáreas) }\end{array}$ & $\%$ \\
\hline Uso agrícola (frutales) & $\begin{array}{l}\text { Uso representado en cultivos } \\
\text { agrícolas de frutales }\end{array}$ & No se aplica & $\begin{array}{l}\text { No se } \\
\text { aplica }\end{array}$ & $349.120,13$ & $41,98 \%$ \\
\hline Uso agrícola y forestal & $\begin{array}{l}\text { Uso constituido por tierras } \\
\text { combinadas con cultivos agrícolas } \\
\text { y con tierras sin uso aparente, } \\
\text { compuesto por especies de } \\
\text { poca altura y tronco leñoso o } \\
\text { semileñoso delgado. }\end{array}$ & $3.502,38$ & $3,75 \%$ & $3.502,38$ & $3,75 \%$ \\
\hline Uso agropecuario & $\begin{array}{l}\text { Uso combinado entre cultivos y } \\
\text { actividades pecuarias }\end{array}$ & $23.817,89$ & $25,51 \%$ & $23.817,89$ & $25,51 \%$ \\
\hline Uso agrícola & $\begin{array}{l}\text { Este uso está constituido por los } \\
\text { cultivos agrícolas transitorios y } \\
\text { permanentes. }\end{array}$ & $54.581,34$ & $58,45 \%$ & $15.461,20$ & $16,56 \%$ \\
\hline $\begin{array}{l}\text { Uso de bosques } \\
\text { productores y } \\
\text { protectores }\end{array}$ & $\begin{array}{l}\text { Corresponde a pequeños relictos } \\
\text { de bosques naturales, secundarios } \\
\text { y ceiba y melina }\end{array}$ & $11.028,86$ & $11,81 \%$ & $11.028,86$ & $11,81 \%$ \\
\hline Uso residencial & $\begin{array}{l}\text { Área constituida por las zonas } \\
\text { habilitadas por los pobladores. }\end{array}$ & 452,4 & $0,48 \%$ & 452,4 & $0,48 \%$ \\
\hline
\end{tabular}

Fuente: PNUD (2015b, p. 14).

Tabla 6. Concentración de la tierra en El Carmen de Bolívar para el año 2011

\begin{tabular}{|c|c|c|c|c|}
\hline 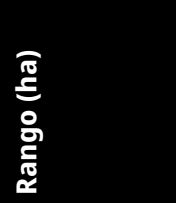 & 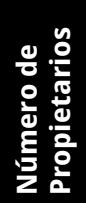 & 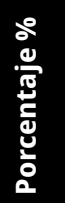 & 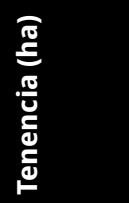 & 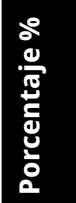 \\
\hline Menos de 1 ha & 209 & 5,1 & 53,85 & 0,05 \\
\hline Entre 1 y 20 & 2.033 & 50 & $16.348,48$ & 16,44 \\
\hline Entre 20 y 500 & 1.818 & 44,7 & $76.814,64$ & 77,25 \\
\hline 500 y más & 10 & 0,2 & $6.221,46$ & 6,26 \\
\hline Total & 4.070 & 100 & $99.438,43$ & 100 \\
\hline
\end{tabular}

Fuente: PNUD (2015b, p. 19).

La concentración de la tierra en El Carmen de Bolívar es muy alta. Las cifras permiten concluir que para el 55,1 \% de los propietarios, la extensión de su tierra no alcanza las veinte hectáreas, que según el Ministerio de Agricultura y Desarrollo Rural constituyen la Unidad Agrícola Familiar para este municipio. Este $55,1 \%$ de los pequeños propietarios tan solo poseen en total el 16,49\% del territorio, mientras que los propietarios con grandes extensiones de tierra, que son el $44,9 \%$, poseen el $83,51 \%$ del territorio, para el año 2011, evidenciando los altos índices de desigualdad.
Pero entre los grandes propietarios también existen índices de desigualdad. Mientas que 1.818 de los propietarios con tenencias entre 20 y 500 hectáreas poseen 76.814 hectáreas, con un promedio de 42,25 hectáreas por propietario, 10 propietarios con 500 o más hectáreas poseen $6.221,46$, con un promedio de 622,1 hectáreas por propietario. Lo anterior atestigua la hiper concentración de la tierra en el 0,2\% de propietarios en El Carmen de Bolívar.

Para entender esta intensa concentración de la tierra en El Carmen de Bolívar, tenemos que remontarnos a los episodios de la violencia, cuando existieron a partir de la década de los noventa del siglo $\mathrm{xx}$ los siguientes actores armados (Alvis, 2017): Compañía Palenque del Bloque Caribe de las FARC-EP; la compañía Jades Jiménez del ERP; las Autodefensas Unidas de Colombia con la estructura Rito Antonio Ochoa; el frente Jaime Báteman Cañón del ELn; el bloque "héroes de los Montes de María" de las Auc.

La disputa entre estos actores conllevó a diferentes masacres, como fuente de terror, desplazamiento y de acumulación (Alvis, 2017, p. 88). Este contexto ocasionó en la subregión de los Montes de María que alrededor de 620 personas fueran 
asesinadas entre 1996 y 2004 , de las que 525 hacen parte de la sociedad civil y 95 son combatientes. Así mismo, se llevaron a cabo aproximadamente 211 hechos de conflictos armados en Montes de María, de los que 64 se concentraron en El Carmen de Bolívar (González, 2017).

Figura 8. Víctimas del conflicto en municipio de Montes de María entre los años 1985 y 2013.

Fuente: Alvis (2017, p. 92).

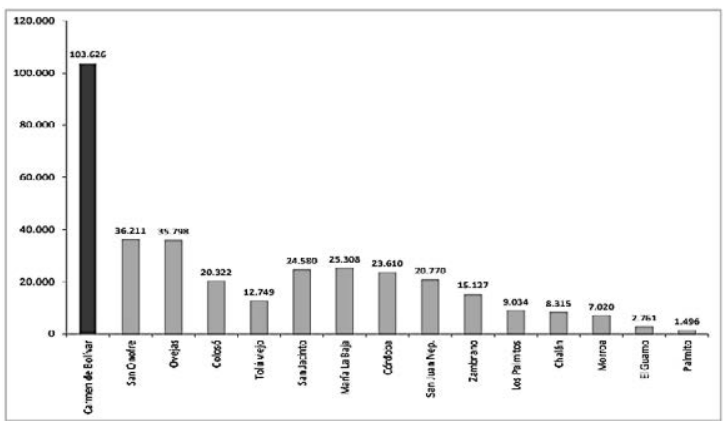

Entre 1985 y 2013 se evidencian más de 600 personas asesinadas, lo que desencadenó el desplazamiento forzado de aproximadamente 120.000 personas, como parte de la reconfiguración del territorio y la inserción del terror en la sociedad civil (ver Figura 8). En los más horrendos escenarios de la extrema violencia, como la masacre del Salado, entre otros, la sociedad montemariana tenía que asistir a la atrocidad de los asesinatos de sus familiares, amigos y conocidos a partir de la más alta sevicia y consternación por parte de los ejércitos paramilitares (Alvis, 2017).

Estos altos índices de violencia en el municipio reconfiguraron el territorio a partir del desplazamiento forzado que contribuyó de gran manera a la hiperconcentración de la tierra en El Carmen de Bolívar. Este desplazamiento forzado, bajo los grupos paramilitares, benefició directa o indirectamente a grandes latifundistas y empresarios (Zableh, 2016, p. 31).

A partir del año 2005, con la desmovilización parcial de las Autodefensas Unidas de Colombia, los índices de violencia se redujeron, claramente por la restructuración del territorio por este actor, y dieron paso a la atracción de diferentes inversionistas que vieron el potencial productivo y geoestratégico con el que cuenta este municipio.
Si bien a partir del año 2005 se vivió una compra masiva de terrenos en El Carmen de Bolívar, durante los años de altos índices de violencia 19982004 se mantuvo una alta compra de terrenos de los campesinos desplazados forzosamente, atestiguando el beneficio directo entre la estrategia de desplazamiento y la compra de terrenos por grandes empresarios y latifundistas.

En la gran concentración de tierra en El Carmen de Bolívar existió un interés, dirigido por el desplazamiento provocado por ciertos empresarios, que se beneficiaron del actuar de los grupos paramilitares; interés al que estos mismos habían colaborado directa o indirectamente en su gestación y que en un primer momento partían de la confrontación con las guerrillas. Pero, al mismo tiempo evidenciaron su estrategia de posesión y control de territorio por medio de la aniquilación física de cualquier contradictor, ya fuera un actor armado o un simple grupo de campesinos (Lizcano, 2018).

Pero no solo existía una relación directa entre algunos empresarios y los diferentes grupos paramilitares en la región, sino que es evidente la participación del Estado en el despojo por las fuerzas militares con acciones conjuntas o en sus omisiones selectivas para dar espacio al control paramilitar. Pero también de las instancias estatales y particulares encargados de las gestiones administrativas de la tierra, en asuntos como el registro, en las compraventas con la participación de notarios corruptos; estos servían como fuente de legalización de las compras de terrenos y en algunos casos de planificación de los despojos y compras forzadas de los territorios de los campesinos de El Carmen de Bolívar (Lizcano, 2018).

\section{Distribución de la tierra en El Carmen de Bolívar}

El Carmen de Bolívar es uno de los municipios con mayores índices de violencia física en las últimas décadas en Colombia. Este municipio cuenta con un alto potencial agropecuario y está posicionado en un corredor entre el centro y sur del país hacia la costa atlántica. El Carmen de Bolívar, para el año 2005, contaba con una población de aproximadamente 67.952 personas, de donde se evidencia un desplazamiento forzado acumulado hasta el año 2011 de 100.191 personas. Aproximadamente, el porcentaje de personas desplazadas alcanzó un 48 
$\%$, lo que supera a la población total del municipio en 2005, evidenciando las altas tasas de violencia y despojo (García et al., 2015).

Así mismo, por lo menos 45 masacres entre 1991 y 2011 como fuente de terror y de restructuración del territorio a partir del desplazamiento forzado y el genocidio como práctica socioeconómica. También se constatan por lo menos 1.955 predios abandonados, derivados de la presión física desde 1970 hasta 2011. Hasta 2015 se observan tan solo 79 predios restituidos de las 1.319 solicitudes, los que sólo representan una pequeña porción del área de predios, calculada en 1.537 hectáreas (García et al., 2015).

En este contexto sombrío, observaremos que la distribución de la tierra en El Carmen de Bolívar para el año 2019 está caracterizada por la inmovilidad en la distribución y redistribución de la tierra en el municipio. En la Tabla 7 podemos evidenciar, por los diferentes rangos, la cantidad de predios, propietarios, área de terreno y el promedio de terreno por propietario en El Carmen de Bolívar para el año 2019, según la UPRA.

La cantidad de predios según los rangos de la Tabla 7 para El Carmen de Bolívar evidencia una alta concentración de la tierra. En los rangos de 500 a 1.000 y de 1.000 a 2.000 hectáreas solo se encuentran nueve propiedades. Mientras que para los predios entre 0,5 y 5 hectáreas se encuentras 678 propiedades. Estas cifras resultan coherentes con el desplazamiento forzado del campo rural al urbano de las familias campesinas, debido a los desplazamientos forzados y el gran acaparamiento de tierras que muestra cómo nueve personas mantienen predios por encima de las 500 hasta las 2.000 hectáreas.

En la Figura 9 se evidencia cómo a menor rango de propiedad y en los rangos medios se concentran la mayor parte de los predios en El Carmen de Bolívar. En los rangos altos se reducen los predios y se concentra la propiedad. Esta concentración es derivada de la violencia ejercida históricamente en la región por los grupos paramilitares en contubernio con los grandes latifundistas y el Estado.

Este alto rango de propiedad y los bajos predios en El Carmen de Bolívar constatan el papel de la reconfiguración del territorio, a partir del masivo desplazamiento forzado y el genocidio como práctica socioeconómica en la región, así como su perpetuación en el tiempo; allí los procesos de

Tabla 7. Distribución de la tierra en El Carmen de Bolívar para el año 2019

\begin{tabular}{|c|c|c|c|c|}
\hline Rango & $\begin{array}{l}\text { Cantidad de } \\
\text { predios }\end{array}$ & $\begin{array}{l}\text { Cantidad de } \\
\text { propietarios }\end{array}$ & Área de terrenos (ha) & $\begin{array}{l}\text { Promedio del } \\
\text { territorio por } \\
\text { propietario }\end{array}$ \\
\hline Hasta 0,5 ha & 160 & 162 & 23,218 & 0,143320988 \\
\hline $0,5-1$ ha & 63 & 65 & 47,6312 & 0,732787692 \\
\hline $1-2,5$ ha & 191 & 203 & 339,6398 & 1,673102463 \\
\hline $2,5-3$ ha & 41 & 41 & 115,092 & 2,807121951 \\
\hline 3 - 5 ha & 223 & 268 & 889,7623 & 3,320008582 \\
\hline $5-10$ ha & 473 & 564 & $3.538,3692$ & 6,273704255 \\
\hline 10 - 20 ha & 799 & 964 & $11.981,672$ & 12,42912075 \\
\hline 20 - 50 ha & 963 & 1259 & $27.957,59$ & 22,20618769 \\
\hline 50 - 100 ha & 240 & 322 & $17.175,459$ & 53,33993354 \\
\hline $100-200$ ha & 118 & 172 & $16.072,957$ & 93,44742384 \\
\hline $200-500$ ha & 56 & 80 & $15.715,383$ & 196,4422913 \\
\hline $500-1.000$ ha & 8 & 8 & $5.294,5893$ & 661,8236625 \\
\hline $1000-2.000$ ha & 1 & 1 & $1.111,5628$ & 1111,5628 \\
\hline Total & 3.336 & 4.109 & $100.262,926$ & \\
\hline
\end{tabular}

Fuente: elaboración propia a partir de uPRA (2019, p. 32). 
restitución de tierras no han trastocado las grandes propiedades.

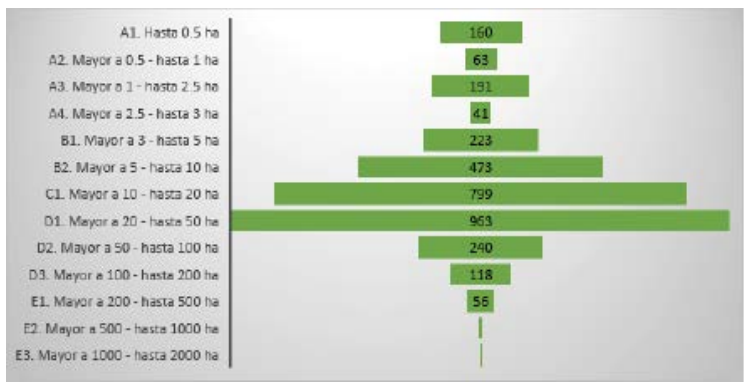

Figura 9. Número de predios por rango de El Carmen de Bolívar para el año 2019.

Fuente: elaboración propia a partir de UPRA (2019, p. 33).

Así mismo, la cantidad de propietarios se solapa parcialmente con los predios en El Carmen de Bolívar. La cantidad de propietarios sigue la lógica de la figura geométrica del rombo, en la que se encuentra una mayor cantidad de propietarios en los rangos bajos y medios, mientras que en los rangos altos los propietarios son pocos (ver Figura 10). Los propietarios se concentran en los rangos medios entre diez y cincuenta hectáreas teniendo en cuenta que para este municipio la unidad agrícola familiar se encuentra calculada entre 35 (mínimo) y 48 hectáreas (máximo) (UPRA, 2019).

La cantidad de propietarios muestra la centralización de la tenencia de la tierra en pocas manos y manifiesta las políticas distributivas y no redistributivas de la tierra, de las leyes agrarias de Colombia, solapando, haciendo invisible y manteniendo la acumulación de tierras bajo la reconfiguración violenta del territorio en El Carmen de Bolívar.

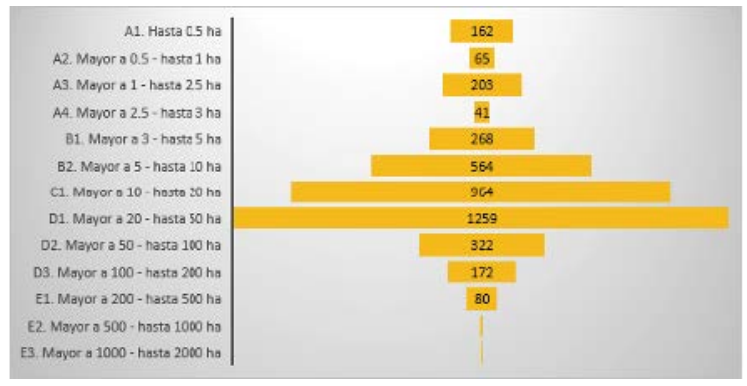

Figura 10. Número de Propietarios según rango en El Carmen de Bolívar para el año 2019.

Fuente: elaboración propia a partir de UPRA (2019, p. 35).
Continuando con el análisis de la distribución de la tierra en El Carmen de Bolívar, observamos como en la distribución de los terrenos por rango se concentra la tierra en los terrenos con mayor área (ver Figura 11). Esta dinámica ratifica la concentración de los terrenos en las grandes haciendas, manifestando la restructuración de la economía en El Carmen de Bolívar, que pasó de una economía familiar y agroalimentaria a una economía de agroindustria y grandes plataformas pecuarias.

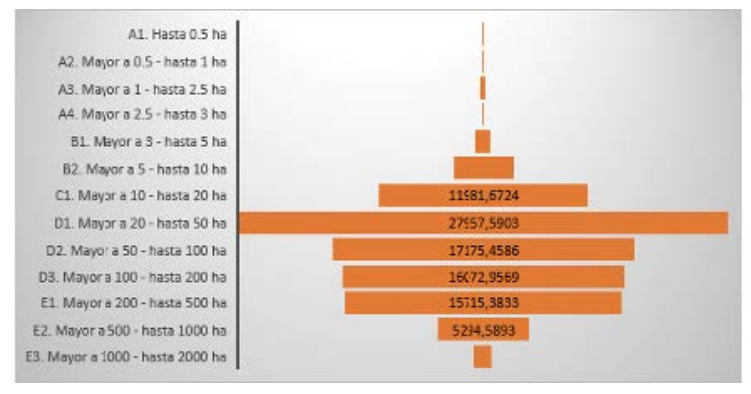

Figura 11. Área de los terrenos por rango en El Carmen de Bolívar para el año 2019.

Fuente: elaboración propia a partir de UPRA (2019, p. 37).

$\mathrm{Al}$ igual que las tendencias generales de la región de los Montes de María, el municipio de Carmen de Bolívar vive una restructuración de su modelo productivo beneficiando a los grandes tenedores y sumiendo en diferentes formas de explotación a grandes capas de la sociedad. Según el profesor Daniels:

[...] en Montes de María la transformación abrupta del territorio, se proyecta con la presencia de modelos de desarrollo desiguales/diferenciados, configurando una estructura productiva heterogénea (producción campesina- ganadería extensiva-agroindustria - minería e hidrocarburos), en donde los efectos nefastos de la violencia asociada al conflicto armado - despojo/desplazamiento/empobrecimiento-, la precariedad institucional territorial y la ausencia de una política de desarrollo rural contribuyen a un escenario de incertidumbre y ambivalencia para las comunidades montemarianas (Amaranto y Daniels, 2016, p. 76).

En la Figura 11 se exhibe una mayor concentración de terreno en los rangos más altos en El Carmen de Bolívar, donde los propietarios del rango de 0,5 hasta 3 hectáreas son 490 aproximadamente 
y cuentan con un área de 525,6 hectáreas, mientras el mayor tenedor de tierra posee 1.111,5 hectáreas. De tal manera que el mayor poseedor de tierras en el municipio cuenta con más del doble de hectáreas que las 490 familias en los rangos más bajos de predios en el municipio.

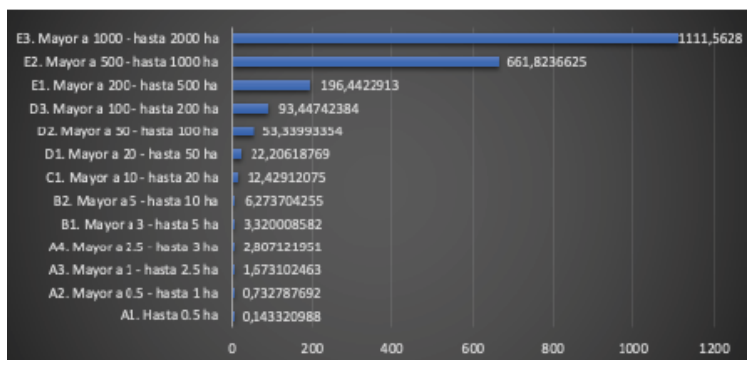

Figura 12. Promedio de hectáreas por propietario según el rango en El Carmen de Bolívar para el año 2019.

Fuente: elaboración propia a partir de UPRA (2019, p. 41).

Por último, el promedio de hectáreas por propietario ratifica la alta concentración de la tierra en El Carmen de Bolívar (ver Figura 12). Los 1.259 propietarios en el rango entre 20 y 50 hectáreas poseen en promedio 22,206 hectáreas, área por debajo de la Unidad Agrícola Familiar para este municipio. Por otra parte, para el rango de 1.000 a 2.000 hectáreas, encontramos un promedio del territorio por propietario de 1.111,5 hectáreas, aproximadamente 50 veces más; es decir, que el propietario con mayor terreno posee 50 veces más que la media de los poseedores en El Carmen de Bolívar.

Así mismo, el promedio del territorio por propietario, en el rango de hasta 0,5 hectáreas es de 0,14 hectáreas, unas 7.756,89 veces menos que el promedio del mayor propietario en El Carmen de Bolívar. Lo anterior nos permite corroborar la extrema desigualdad de este municipio, la supervivencia de la acumulación de tierra y la incapacidad institucional de revertir esta lógica, tras la puesta en marcha de la restitución de tierras al principio de la segunda década del siglo xxI.

\section{Discusión: el modelo de las Zidres}

El problema de la tierra sigue apareciendo en el horizonte próximo como una fuente de conflictos sociales en Colombia. Tal realidad parece una contradicción y resulta sumamente paradójica.
Existen varios ingentes esfuerzos desde el Estado que buscan resolver los conflictos por la tierra, entre los que se destacan el proceso de restitución de tierras y la reforma rural integral como resultado del proceso de paz; incluso, con bastantes limitaciones, la ley 160 de 1994 también apunta a este objetivo. Esto a pesar de los esfuerzos de encaminar el país por sendas de cambios, los cuales han sido principalmente: institucionales; sobre aspectos nodulares como la resolución pacífica de las diferencias políticas; y de la búsqueda de poner fin a una problemática de profundo anclaje histórico como es la distribución de la tierra y los derechos de propiedad. Sin embargo, los procesos de concentración y acaparamiento de tierras no parecen revertirse; por el contrario, parece profundizarse bajo un nuevo modelo de inclusión de las alianzas productivas, que es el eje nodal a partir del cual se construye el modelo de desarrollo de las denominadas Zidres, dispuestas en la ley 1776 de 2016.

En términos productivos, Colombia no ha conseguido cambiar la fuente de recursos para sustentar su estructura macroeconómica. Son recurrentes las crisis o desaceleraciones en la producción por cuenta de las fluctuaciones externas de algunos productos básicos. La crisis del petróleo y una pavorosa destrucción de la escasa estructura industrial por cuenta de la denominada "enfermedad holandesa", han conducido a que la política económica privilegie la explotación a gran escala del subsuelo para sustraer metales como el oro, carbón, níquel, entre otros (Arias Hurtado, 2017).

Según la Organización de las Naciones Unidas para la Alimentación y la Agricultura (FAO) Colombia es uno de los cinco países más importantes para ser despensa mundial de alimentos por su ubicación y disponibilidad de tierras. En los últimos años, los distintos gobiernos en Colombia han tratado de responder al llamado de la FAO como despensa de alimentos; que permita el crecimiento económico del país hacia la competitividad externa fundada en la especialización en la producción de algunos commodities agrícolas bajo el modelo de plantación a gran escala. Así es en las áreas rurales, en las que se pretende extraer gran parte de la riqueza futura. 
Las aproximaciones al espacio rural desde la perspectiva de los agronegocios, las estrategias de las alianzas productivas y el énfasis empresarial a gran escala tienen en común el considerarlo como una suerte de "baldío social"; esto es, un espacio vacío a la espera de inversores que lo vuelvan productivo y desarrollen dichas regiones desde su perspectiva centrada principalmente en el crecimiento económico. Sin embargo, tales intenciones productivas chocan con otros intereses y cosmovisiones. En el espacio rural colombiano confluyen actores con tradición ancestral sobre los territorios o con formas productivas que se apartan de modelos intensivos en capital. De esta manera se tiene una conflictividad en materia productiva y social, en la que distintos agentes luchan por el reconocimiento de sus derechos o de sus pretensiones.

A pesar de las múltiples modalidades de ordenamiento social y productivo de la tierra en Colombia, en los últimos años se ha intentado ensayar un modelo de alianza virtuosa entre el capital agroindustrial y los medianos y pequeños trabajadores rurales; para ello, diferentes gobiernos han buscado la aprobación de un marco normativo que les permita su desarrollo. Por denuncias y escándalos de corrupción estos modelos no lograban su aprobación en el legislativo. Sin embargo, la ley 1776 de 2016, por medio de la cual se crean las Zidres, logró su paso por el Congreso, que aprobó un modelo particular de ordenamiento social, económico y productivo de la propiedad; no obstante, este nuevo marco normativo fue aprobado bajo fuertes controversias políticas, económicas, sociales e incluso jurídicas.

Hubo oposición de distintos sectores sociales con el contenido de la norma (comunidades étnicas y campesinas), y esta se demandó ante la Corte Constitucional por considerar que se afectaban los derechos fundamentales, como el acceso progresivo a la tierra, la consulta previa, libre e informada, entre otros argumentos esbozados. A pesar de esto, la ley 1776 de 2016 fue declarada exequible por el máximo tribunal constitucional. La decisión de la asequibilidad de la ley fue dividida al interior de la Corte Constitucional (de un total de nueve votos, seis magistrados votaron a favor de la ley; tres magistrados lo hicieron en contra). En una decisión controvertida, que no guarda plena coherencia con su precedente de especial protección constitucional hacia los trabajadores agrarios, la Corte introduce algunos elementos de modulación; lo hace con el fin de aminorar los impactos sobre los territorios ancestrales y garantizar la autonomía de los entes territoriales en la definición de políticas de ordenamiento territorial.

En su sentencia C-077 de 2017, la Corte Constitucional estudió dos potentes demandas dirigidas a atacar la médula de las Zidres: el modelo de zonificación aparejado al uso de los baldíos y el modelo de asociación de alianzas productivas. A pesar de sus importantes consideraciones sobre el corpus iuris de los derechos de los campesinos, declaró en su mayoría los artículos de la ley Zidres ajustados a la Constitución. En general, la Corte Constitucional consideró que antes que desconocer los derechos fundamentales de los campesinos y los trabajadores agrarios, la ley Zidres es un modelo económico que desarrolla los mandatos constitucionales; que está dentro de la órbita de libertad del legislador proponer un determinado modelo de desarrollo rural que, en su criterio, es respetuoso del corpus iuris de los derechos de los campesinos.

\section{Conclusiones}

El plateamiento sobre el cual se soporta la ley 1776 de 2016, por medio de la cual se crearon las zonas Zidres, es generar espacios excepcionales dentro del territorio nacional para el desarrollo de proyectos agroindustriales a gran escala que vinculen a los campesinos; para de esta forma, "promover el acceso y formalización de la tierra de los campesinos", como lo estipula el artículo 2 de la ley.

Además de contar con paquete amplio de incentivos económicos y fiscales dirigidos a los empresarios del campo que postulen proyectos productivos ante el Ministerio de Agricultura, el modelo de las zonas Zidres está libre de las limitaciones que imponía la ley 160 de 1994 en términos de extensión de tierra y su propiedad. En efecto, para la creación de las zonas podrán utilizarse bienes tanto públicos como privados, sin límite de extensión, la cual está supeditada al tipo de proyecto productivo a implementar. Además, la entrega de los bienes inmuebles de la Nación, según el artículo 13, es decir los baldíos, se hace a través de modalidades contractuales no traslaticias de dominio, lo 
cual permite también superar las limitaciones que implicaba la ley 160 de 1994.

Las zonas Zidres configuran un proyecto que busca entregar grandes plataformas de territorio a favor de empresas nacionales y trasnacionales con el fin de generar un encadenamiento productivo y responder a las necesidades del mercado. Según la UPRA, hay un potencial de 93.386,04 hectáreas en El Carmen de Bolívar, en contraste con las 101.262,93 hectáreas totales de los predios en este municipio.

Para el municipio de María La Baja se encuentran 53.862,4 hectáreas potenciales para Zidres, lo que representaría casi la totalidad de la actual área de los predios en el municipio con 54.766,8 hectáreas para el año 2019.

Es decir, que el potencial de las Zidres para el año 2019 es aproximadamente un 93,73\% del total del área de los predios en El Carmen de Bolívar. Este proyecto intensificará aún más la desigualdad en el acceso de la tierra, anudado a los problemas sociales, laborales, ecológicos y culturales, ya lesionados a partir del desplazamiento y acumulación de las tierras en esta región.

Estos proyectos de Zidres se enfocarán en la monoproducción agroindustrial con grandes adjudicaciones por parte del Estado, en contraposición a la baja tasa de restitución de tierras para la región de los Montes de María.

La conclusión general de la investigación es que el modelo de las zonas Zidres profundiza en las causas del conflicto social en Colombia como es el reparto inequitativo de la tierra, reforzando la estructura agraria bimodal entre grandes latifundios y la fragmentación de pequeños propietarios, que serían incorporados por el modelo Zidres, lo cual podría generar nuevos conflictos por la tierra en el país.

\section{Referencias}

Agudelo, L., y Cardozo, F. (1985). Estudio Socioeconómico distrito de El Carmen de Bolívar. Bogotá: Intituto Colombiano Agropecuario.

Alcaldía de María la Baja. (2016, 23 de febrero). Información del Municipio. Alcaldía de María La Baja - Bolívar. Recuperado de http://www.marialabaja-bolivar. gov.co/MiMunicipio/Paginas/Informacion-del-Municipio.aspx

Alvis, J. (2017). Desarrollo local en zonas de posconflicto armado. México, D. F.: Universidad de León.
Amaranto, J., y Daniels, P. (2016). La transformación de la estructura productiva de los Montes de María: de despensa agrícola. Memorias: Resvista digital de historia y arqueología desde el caribe colombiano, (29), 52-83. Recuperado de http://www.scielo. org.co/scielo.php?script $=$ sci_arttext $\&$ pid $=S 1794$ $88862016000200004 \& \operatorname{lng}=e n \& n r m=i s o \& \operatorname{lng}=e s$

Arias Hurtado, C. (2017). Neoextractivismo en América Latina y Colombia: una reflexión desde la ecología política. Revista Controversia, (208), 15-53.

Bennewitz, E. v. (2017). Land Tenure in Latin America: from Land Reforms to CounterMovement to Neoliberalism. Acta Universitatis Agriculturae et Silviculturae Mendelianae Brunensis, 7, 1793-1798. doi: https:/doi. org/10.11118/actaun201765051793

Bernstein, H. (2016). Dinámicas de clase y transformación agraria. Barcelona: Icaria Editorial .

Congreso de la Republica de Colombia. (1994). Ley 160. Diario oficial 41.479.

Congreso de la Republica de Colombia. (2016). Ley 1776. Diario oficial 49.770. Recuperado de https://dapre. presidencia.gov.co/normativa/normativa/LEY\%20 1776\%20DEL\%2029\%20DE\%20ENERO\%20DE\%20 2016.pdf

Cubillos, R. (2011). Transformaciones territoriales a partir del abandono y despojo de tierra asociada a la accion de grupos armados caso María la Baja departamento de Bolivar (Tesis de maestría). Pontificia Universidad Javeriana, Colombia. Recuperado de https://repository.javeriana.edu.co/bitstream/handle/10554/1083/ CubillosRaquelVictorino2010.pdf?sequence $=1 \&$ isAllowed $=\mathrm{y}$

Equipo Tierras y Víctimas del Cinep/ Programa por la Paz. (2012). La otra carfa de la palma en María la Baja. Cien días. Recuperado de https://www.cinep.org.co/publicaciones/PDFS/20121101h.maria_baja76.pdf

Fajardo, D. (2017). Estudio sobre los orígenes del conflcto social armado, razones de su persistencia y sus efectos más profundos en la sociedad colombiana. Comisión Histórica del conflicto y sus víctimas. Recuperado de https://www.ambitojuridico.com/BancoMedios/Documentos\%20PDF/ estudio-sobre-los-origenes-del-conflicto-social-armado-razones-de-su-persistencia-y-sus-efectos-mas-profundos-en-la-sociedad-colombiana--1469487289.pdf

Fajardo, D. (2018). Agricultura, campesinos y alimentos (1980 - 2010). Bogotá: Universidad Externado de Colombia.

García, P., Reyes, L., Ochoa, G., Pardo, B., Herrero, J., y Zableh, O. (2015). Informe sobre el estado actual $e$ impactos del proceso de restitución de tierras. Bogotá: 
Observatorio de Restitucion y Regulación de Derechos de Propiedad Agraria.

González, D. (2017). El sesgo Anti-campesino del Estado. Bogotá: Universidad Colegio Mayor de Nuestra Señora del Rosario.

Holt-Giménez, E., y Raj, P. (2012). Rebelión Aliemntaria: La crisis y el hambre por la justicia. México, D. F.: Universidad Autónoma de Zacatecas-Miguel Ángel Porrúa.

Ibáñez, A. (2008). El desplazamiento forzoso en Colombia: un camino sin retorno hacia la pobreza. Bogotá: Ediciones Uniandes.

Incora. (2002). Colombia Tierra y Paz Experiencias y Caminos Para La Reforma Agraria Alternativas Para El Siglo xxi. Bogotá: Instituto Colombiano de la Reforma Agraria.

Indepaz. (2013). Documento de línea base agroindustria de la palma aceitera- María La Baja (Bolívar). Recuperado de http://palma.indepaz.org.co/wpcontent/uploads/2012/11/L\%C3\%ADnea-base-palmapreliminar_190213.pdf

Juníeles, I. (2017). Retos y oportunidades para la transformación del campo: Programas de Desarrollo con Enfoque Territorial. Dejusticia. Recuperado de https:// www.dejusticia.org/column/retos-y-oportunidadespara-la-transformacion-del-campo-programas-dedesarrollo-con-enfoque-territorial/

Lizcano, M. (2018). Así se disputan la tierra en Colombia. Mongabay. Recuperado de https://es.mongabay. com/2018/07/robo-de-tierra-en-colombiaacaparamiento/

Molano, A. (2011). Montes de María. El espectador. Recuperado de https:/www.elespectador.com/ noticias/nacional/montes-de-maria-articulo-271613

Mollett, S. (2016). The Power to Plunder: Rethinking Land Grabbing in Latin America. Antipode, 48(2), 412-432. DOI: https://doi.org/10.1111/anti.12190

Moreno, Y. (2016). Cambio de la cobertura de la tierra en María La Baja, Bolívar, entre 1984 y 2015 por proceso de despojo de tierras. Biblioteca General Alfonso Borrero Cabal S. J. Recuperado de https://repository.javeriana.edu.co/handle/10554/20484

Oxfam. (2016). Colombia: las falacias detrás de $\mathrm{Zi}$ dres, una ley de "subdesarrollo rural". Oxfam International. Recuperado de https://www. oxfam.org/es/colombia-las-falacias-detras-de-zidres-una-ley-de-subdesarrollo-rural

Oxfam América. (2017). Radiografia de la desigualdad: lo que nos dice el úlltimo censo agropecuario sobre la distribución de la tierra en Colombia. Oxfam Inter- national. Recuperado de https://www.oxfam.org/es/ informes/radiografia-de-la-desigualdad

Paz, A., y Latam, M. (2018). Un millon de Hogares campesinos en Colombia tienen menos tierra que una vaca. $\mathrm{Se}$ mana Sostenible. Recuperado de https://sostenibilidad. semana.com/impacto/articulo/concentracion-de-latierra-en-colombia-el-1-por-ciento-de-las-fincas-masgrandes-ocupan-el-81-por-ciento-de-la-tierra/40882

PNUD. (2015a). Perfil productivo municipio María la Baja. Recuperado de https://issuu.com/pnudcol/docs/perfil_productivo_mar__a_la_baja

PNUD. (2015b). Perfil productivo El Carmen de Bolívar. Recuperado de https://issuu.com/pnudcol/docs/perfil_productivo_municipal_de_el_c/15

Pontificia Universidad Javeriana. (2016). Historia del distrito de riego de María la Baja - Bolívar: Más motivos para decir que el agua es nuestra. Recuperado de http://rutasdelconflicto.com/especiales/acuatenientes/ documentos/riego-archivo2.pdf

Reyes, A (2016) . Guerreros y campesinos. Despojo y restitución de tierras en Colombia. Bogotá: Ariel.

Rivillas, C., y Yepes, S. (2011). Conflicto de tierras en el municipio de Carmen de Bolivar: Reclamación y Restitucion de bienes en contexto de violencia. Universidad de Cartagena Repositorio UdeC. Recuperado de http://repositorio.unicartagena.edu. co/handle/11227/200

UPRA. (2019). Respuesta Derecho de peticion 2019: Distribución de la tierra en María la Baja y El Carmen de Bolivar. Bogotá: PNUD.

Vega, R. (2015). La dimensión internacional del conflicto social y armado en Colombia. Injerencia de los Estados Unidos, Contrainsurgencia y Terrorismo de Estado. Recuperadodehttp://www.centrodememoriahistorica. gov.co/descargas/comisionPaz2015/VegaRenan.pdf

Zableh, J. (2019). Normas Rústicas en el mercado de tierras campesinas: El caso de El Carmen de Bolívar (Tesis de maestría). Universidad del Norte, Colombia. 